\title{
The Ongoing Journey of a Shigella Bioconjugate Vaccine
}

\author{
Patricia Martin * and Cristina Alaimo *
}

LimmaTech Biologics AG, 8952 Schlieren, Switzerland

* Correspondence: patricia.martin@1mtbio.com (P.M.); cristina.alaimo@lmtbio.com (C.A.)

\begin{abstract}
Shigellosis is a serious disease with a major impact, especially in low-income countries where mortality and morbidity are high. In addition, shigellosis among travelers and military personnel is a cause of significant morbidity and contributes to the increase in antimicrobial resistance. The World Health Organization (WHO) considers the development of a Shigella vaccine a priority for public health. Over the past 60 years, several efforts to develop a Shigella vaccine have been pursued, without success. The principle of preventing shigellosis with a conjugate vaccine was demonstrated in the 1990's, but this vaccine was not further developed. Bioconjugation is an innovative technology that allows the production of conjugate vaccines in a biological environment to preserve native immunogenic structures. In this review, we describe the journey of the bioconjugate Shigella vaccine, one of the most advanced clinical programs for a Shigella vaccine.
\end{abstract}

Keywords: Shigella; vaccines; O-antigen; bioconjugate

\section{Introduction}

Shigellosis is caused by infection with Gram-negative Shigella spp. bacteria, a genus

check for updates

Citation: Martin, P.; Alaimo, C. The Ongoing Journey of a Shigella Bioconjugate Vaccine. Vaccines 2022, 10, 212. https://doi.org/ 10.3390/vaccines10020212

Academic Editors: Duncan Steele and Calman A. MacLennan

Received: 17 December 2021

Accepted: 19 January 2022

Published: 29 January 2022

Publisher's Note: MDPI stays neutral with regard to jurisdictional claims in published maps and institutional affiliations.

Copyright: (C) 2022 by the authors. Licensee MDPI, Basel, Switzerland. This article is an open access article distributed under the terms and conditions of the Creative Commons Attribution (CC BY) license (https:// creativecommons.org/licenses/by/ $4.0 /)$. belonging to the Enterobacteriaceae family and encompassing four species: S. dysenteriae, S. boydii, S. flexneri and S. sonnei. In particular, the flexneri and sonnei species have been identified by the GEMS study [1] as the most prevalent species $(65.9 \%$ and $23.7 \%$ of Shigella case isolates, respectively), with five flexneri serotypes accounting for $89.4 \%$ of $S$. flexneri cases, namely serotypes $2 \mathrm{a}, 6,3 \mathrm{a}, 2 \mathrm{~b}$ and $1 \mathrm{~b}$ [2].

Shigellosis has been reported by WHO as the leading bacterial cause of diarrhoea, accounting for approximately 212,000 deaths-about $13 \%$ of all deaths due to diarrhoea [3]. Such clinical outcomes follow the disruption of the intestinal epithelium as a result of invasion by Shigella microorganisms, which are able to survive to macrophage phagocytosis, induce macrophage death and disseminate to adjacent cells [4].

Shigellosis is estimated to lead to around 188 million infections annually, including 62.3 million cases in children younger than 5 years [5]. This disease is one of the major causes of morbidity and mortality [6] due to diarrhoea not only among children in lowincome countries, but also in travellers and deployed military personnel visiting regions of endemicity. Good hygiene practices, clean water and sanitation are important to reduce transmission of the disease. However, the technical difficulties in implementing such measures, as well as the low infectious dose, make it very challenging to control bacterial spread in areas with poor sanitation. The standard treatment for shigellosis focuses on oral rehydration and antibiotic therapy. However, Shigella spp. have acquired resistance to many antibiotics making treatment more difficult and expensive [7]. Though higher for travellers and children or infants in shigellosis-hyperendemic regions, the risk of shigellosis is also increasing in industrialized countries. Outbreaks of shigellosis are increasingly reported, and resistance has increased markedly since 2013. As inexpensive oral antibiotics such as ampicillin and trimethoprim become less effective, alternative drugs such as ciprofloxacin and azithromycin are being used routinely to treat infections. Still, about 77,000 Shigella infections in the United States are reported every year to be resistant to such treatments [8], and accordingly, the CDC (Center for Disease Control and 
Prevention) considers antibiotic-resistant Shigella a serious threat. Similarly, the incidence of antibiotic-resistant Shigella strains has been increasing in LMICs, with pooled values of multidrug-resistant strains generally above $50 \%$ for both S. flexneri and S. sonnei across Asia, Africa and South America, and above $70 \%$ for resistance to ampicillin and tetracycline, or tetracycline and sulphamethoxazole trimethoprim/cotrimoxazole [9].

As initial treatment can fail, resistant infections can last longer than infections with susceptible bacteria, with consequently higher costs for the healthcare system. Therefore, prevention of shigellosis by a vaccine will have an impact well beyond disease and death, and will also slow the spread of antibiotic resistance. Ultimately, as humans are the primary reservoir for Shigella, an affordable and effective vaccine could potentially lead to eradication of shigellosis [10]. In line with these thoughts, the WHO's Product Development for Vaccines Advisory Committee (PDVAC) has identified development of a Shigella vaccine as a priority for LMICs and an important goal for public health [3].

Although several Shigella vaccine candidates are in development, no licensed vaccine is available yet. Multiple strategies have been followed, including orally administered, live-attenuated [11-13] or killed Shigella vaccines [14], and recombinant Shigella vaccines administered parenterally [15-18]. Most of these candidates have so far reached phase 1 or 2 in clinical development, providing data on their safety and immunogenicity, and a few have also been tested for efficacy in human challenge models of Shigella infection [19-21] or in field trials $[10,22,23]$. To the best of our knowledge, the most advanced ongoing clinical programs are those with the recombinant and parenterally administered candidates; the monovalent S. flexneri 2a synthetic conjugate SF2a-TT15 (NCT04602975), previously proven to be safe and immunogenic in healthy adults [15]; the GMMA multivalent candidate altSonflex1-2-3 (NCT05073003), whose monovalent S. sonnei precursor was shown to be safe and immunogenic in healthy adults but failed to demonstrate vaccine efficacy in the sonnei challenge model $[17,20,24]$; the multivalent bioconjugate S4V (NCT04056117), for which safety, immunogenicity and efficacy were shown with its S. flexneri 2a component $[19,25]$. These three candidates are all currently being tested in paediatric populations in Kenya. In addition, a phase 3 study in China with a bivalent S. flexneri-S. sonnei conjugate was just announced (NCT05156528), and a phase 1 with a live, oral, combined Shigella-ETEC vaccine candidate (NCT04634513) and a phase 2 challenge trial with an oral live-attenuated S. sonnei vaccine candidate (NCT04242264) will start soon.

In this review, we describe the clinical development of the Shigella bioconjugate, one of the most advanced Shigella vaccine candidates currently in development.

\section{O-Antigen-Based Shigella Vaccines: From Chemical to Bioconjugates}

A glycoconjugate is a hybrid molecule composed of a carrier protein and multiple polysaccharide chains, wherein the polysaccharides are covalently linked to the protein. This linkage of the antigenic polysaccharide to a carrier protein has brought significant advances in the field of vaccinology, eliciting a T-cell-dependent response characterized by the induction of immunological memory and improved immunogenicity [26,27]. This is particularly relevant for some populations at high risk of developing disease, such as children, elderly or immunocompromised individuals, where polysaccharides alone generally fail to mount an adequate and persistent immune response [28-31]. Indeed, glycoconjugate vaccines have been shown to be safe and effective for different pathogens (i.e., Neisseria meningitidis, Streptococcus pneumonia, Haemophilus influenzae) for more than 30 years [32-34].

Bioconjugates are glycoconjugates produced in vivo in bacterial cells (Figure 1). At the core of the bioconjugation is PglB, a bacterial enzyme capable of forming a specific linkage between a glycan and defined sites on a protein moiety whilst preserving the conformation of all antigenic components [35,36]. Using recombinant DNA technologies, the Escherichia coli glycan biosynthesis machinery is genetically modified to produce the target polysaccharides and transfer them to acceptor proteins. In the bioconjugation process, the glycoconjugate vaccine is produced entirely in $E$. coli in a single-step process, resulting in 
advantages for process reproducibility and robustness, while decreasing manufacturing cost. Using this technology, several vaccines against different pathogens including Shigella (see Table 1) have been developed and tested in clinical trials. Aside from a few bioconjugates against Gram-positive bacteria such as Staphylococcus aureus or S. pneumoniae [37], the majority of bioconjugates have so far targeted Gram-negative bacteria such as Shigella, and in particular the O-antigen expressed on the surface of these microorganisms.

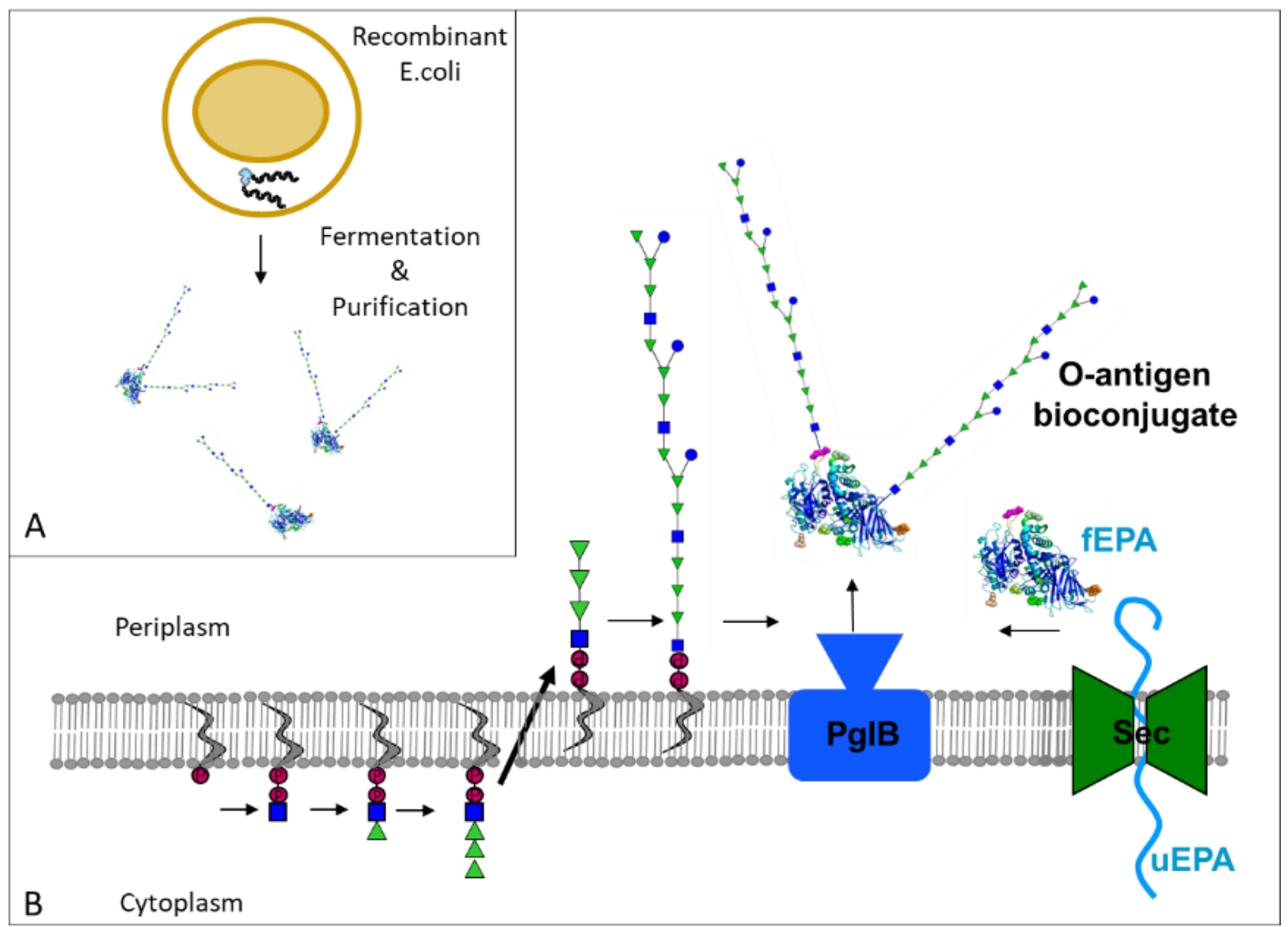

Figure 1. (A) Bioconjugates are purified following fermentation and osmotic shock of recombinant E.coli cells expressing the soluble glycoproteins in the periplasm. (B) Key steps of the in vivo assembly of an $\mathrm{O}$-antigen bioconjugate; $\mathrm{O}$-antigen repeating units are assembled in the cytoplasm on undecaprenol (grey s-shaped line)-pyrophosphate (pink circles with P) lipids, transferred into the periplasm and then polymerized; in parallel, unfolded carrier protein (uEPA) is transferred to the periplasm by the SEC translocation pore (green); in the periplasm, EPA folds (fEPA) and the oligosaccharyltransferase PglB transfers the O-antigen polysaccharide from the undecaprenol pyrophosphate donor to consensus sequences present in the carrier protein EPA, forming a covalent bond. The example illustrates a bioconjugate with the Shigella flexneri 2a O antigen. The O antigen is represented using the monosaccharide nomenclature of the Consortium for Functional Glycomics (http:/ / www.functionalglycomics.org/static/consortium/Nomenclature.shtml (accessed on 17 December 2021)). 
Table 1. Summary of clinical studies conducted with Shigella bioconjugates.

\begin{tabular}{|c|c|c|c|c|}
\hline Study ID & Bioconjugate & Doses * \& schedule & Number $(n)$ \& Age & Results \\
\hline $\begin{array}{c}\text { NCT01069471 } \\
\text { Phase I, } \\
\text { Switzerland, in } 2010\end{array}$ & $\begin{array}{c}\text { Vaccine against } \\
\text { S.dysenteriae } \\
\text { (GVXN SD133-EPA) }\end{array}$ & $\begin{array}{c}2 \mu \mathrm{g} \text { PS } \\
2 \mu \mathrm{g} \mathrm{PS}+\mathrm{AlOH}_{3} \\
10 \mu \mathrm{g} \text { PS } \\
10 \mu \mathrm{g} \text { PS }+\mathrm{AlOH}_{3} \\
2 \text { injections: } \\
\text { Day } 0 \text { and } 2 \text { months }\end{array}$ & $\begin{array}{c}n=40 \\
18-50 \text { years }\end{array}$ & $\begin{array}{ll}\text { - } & \text { No safety concerns } \\
\text { - } & \text { Increase in anti-O1 serum } \\
\text { IgG at day } 30 \text { vs. baseline } \\
\text { - } \quad \text { No further/significant } \\
\text { anti-O1 serum IgG increase } \\
\text { after second dose or } \\
\text { with adjuvant } \\
\text { Anti-O1 serum IgG titers } \\
\text { maintained for } 5 \text { months } \\
\text { (last evaluation) }\end{array}$ \\
\hline $\begin{array}{c}\text { NCT02388009 } \\
\text { Phase I, US, in } 2015\end{array}$ & $\begin{array}{l}\text { Vaccine against } \\
\text { S. flexneri-2a } \\
\text { (Flexyn2a-EPA) }\end{array}$ & $\begin{array}{c}10 \mu \mathrm{g} \text { PS } \\
10 \mu \mathrm{g} \text { PS }+\mathrm{AlOH}_{3} \\
\text { Placebo } \\
2 \text { injections: } \\
\text { Day } 0 \text { and } 1 \text { month }\end{array}$ & $\begin{array}{c}n=30 \\
18-50 \text { years }\end{array}$ & $\begin{array}{ll}\text { - } & \text { No safety concerns } \\
\text { - Increase in anti-2a serum } & \text { IgG, IgA and SBA titers } \\
\text { following vaccination } \\
\text { No further/significant } \\
\text { anti-2a serum IgG increase } \\
\text { after second dose or } \\
\text { with adjuvant } \\
\text { Additionally, for the } \\
\text { phase Ilb: } \\
\text { Positive correlation between } \\
\text { immune response and } \\
\text { protection against shigellosis } \\
\text { Vaccine efficacy against } \\
\text { shigellosis: } 30 \% \text { to } 50 \% \\
\text { (depending on } \\
\text { outcome definition) } \\
\text { Vaccine efficacy against } \\
\text { more severe diarrhea }>70 \% \\
\text { Vaccination reduced }\end{array}$ \\
\hline $\begin{array}{l}\text { NCT02646371 } \\
\text { Phase IIb, US, in } \\
2016\end{array}$ & & $\begin{array}{c}10 \mu \mathrm{g} \text { PS } \\
\text { Placebo } \\
2 \text { injections: } \\
\text { Day } 0 \text { and } 1 \text { month }\end{array}$ & $\begin{array}{c}n=67 \\
18-50 \text { years }\end{array}$ & $\begin{array}{l}\text { constitutional } \\
\text { enteric symptoms } \\
\text { Vaccination reduced } \\
\text { shigellosis disease score }\end{array}$ \\
\hline $\begin{array}{l}\text { NCT04056117 } \\
\text { Phase I/II, Kenya, } \\
\text { Started in } \\
\text { 2019, ongoing }\end{array}$ & $\begin{array}{c}\text { Vaccine against } S \text {. } \\
\text { flexneri } 2 \mathrm{a}, 3 \mathrm{a}, 6 \text { and } \\
\text { sonnei } \\
(\mathrm{S} 4 \mathrm{~V}-\mathrm{EPA})\end{array}$ & $\begin{array}{ll}\text { - } & \text { Two Vaccine doses: } \\
\text { Medium and High } \\
\pm \mathrm{AlOH}_{3} \\
\text { - } 2 \text { injections: day } 0 \\
\text { and } 1 \text { month } \\
\text { Two Vaccine doses: } \\
\text { Medium and High } \\
\pm \mathrm{AlOH}_{3} \\
\text { - } 3 \text { injections: day0, } 1 \\
\text { and } 7 \text { months } \\
\text { Four Vaccine doses: } \\
\text { Very Low, Low, } \\
\text { Medium and High } \\
\pm \text { AlOH } \\
\text { - } 3 \text { injections: day } 0,3 \\
\text { and } 9 \text { months }\end{array}$ & $\begin{array}{c}n=16 \\
18-50 \text { years } \\
n=48 \\
2-5 \text { years } \\
n=528 \\
9 \text { months }\end{array}$ & Ongoing, enrollment completed \\
\hline
\end{tabular}

* doses are indicated as amount of specific O-antigen polysaccharides (PS) conjugated to EPA.

Based on a combination of challenge studies in volunteers, epidemiological surveillance and nonhuman primate studies, the O-antigen on the bacterial cell surface lipopolysaccharide of Shigella spp. has been identified as a key antigenic target, and therefore, a focus for vaccine design. Back in the 1990's, Robbins and coworkers produced conjugate vaccines consisting of purified Shigella polysaccharide conjugated to a protein carrier [38]. Three chemically conjugated Shigella O-antigen vaccines [39] have been tested in clinical phases; Shigella dysenteriae type 1 polysaccharide conjugated to tetanus toxoid and S. flexneri $2 \mathrm{a}$ and S. sonnei polysaccharides both conjugated to recombinant Pseudomonas aeruginosa exoprotein A (EPA). The three conjugates were shown to be safe and immunogenic. Fur- 
thermore, the $S$. sonnei conjugate vaccine was shown in a phase 3 trial to be efficacious in Israeli soldiers and children above 3 years of age $[22,40,41]$. This demonstrated the validity of Shigella $\mathrm{O}$ antigens as vaccine targets and that parenteral immunization can be efficacious against shigellosis.

However, none of these conjugates were further developed. Following the agedependent immune response observed in the field trial in Israeli children, with a drop in efficacy below the age of 3, further effort was invested in the S. sonnei chemical conjugate, generating different conjugate configurations with lower molecular mass oligosaccharides comprising the LPS core plus a few O-antigen repeating units [42]. When tested preclinically, such $S$. sonnei chemical conjugates proved to be more immunogenic than the precursor; however, no further reports were published on their development. The high complexity of such a chemical conjugation approach, which is likely to result in a difficult and costly GMP manufacturing process, as well as the discrepancy between the length of the conjugated glycan and its bacterial target, could be postulated as reasons why this S. sonnei conjugate was not developed further. The Shigella bioconjugate belongs to the next generation of such chemical conjugates, with which it shares the structural characteristics of polysaccharide moieties linked to a protein carrier, but at the same time differs because of its unique biosynthetic process, which ultimately results in epitope preservation and conserved glycan composition.

\subsection{Shigella Dysenteriae Bioconjugate Vaccine}

S. dysenteriae is not a common cause of endemic shigellosis but rather of epidemic outbreaks, as seen in Central America, Central Africa, and Southeast Asia, or of vicious outbreaks in confined populations, most notably during refugee situations.

As a proof of principle for the technology, the first bioconjugate vaccine evaluated in humans was against Shigella dysenteriae [43]. The O-antigen polysaccharide of $S$. dysenteriae type $\mathrm{O} 1$ was bioconjugated to a genetically detoxified version of P. aeruginosa exotoxin $\mathrm{A}$ (EPA). The vaccine was produced in E. coli, purified, and characterized for clinical testing. A phase 1 study in healthy volunteers was conducted in Switzerland [44] with the objective of demonstrating the safety and immunogenicity of the $S$. dysenteriae bioconjugate (called GVXN SD133). The vaccine was used alone or in combination with Alum hydroxide at two different polysaccharide doses, 2 or $10 \mu \mathrm{g}$, and administered twice to 40 healthy subjects, on day 0 and day 60 . In summary, both doses of this prototype vaccine were well-tolerated and showed an acceptable safety profile, similar to other licensed conjugate vaccines. It elicited statistically significant O1-specific serum IgG and IgA responses compared to baseline in all groups independent of the formulation and dose of the vaccine, with no significant difference observed between groups. The same level of systemic response (in terms of O1-specific serum antibodies) was detected at the end of the trial, about 5 months later (see Table 1). Functionality of the antibodies raised against the protein carrier, EPA, was also demonstrated via in vitro neutralization assay, confirming that the native configuration of the protein carrier is preserved during the bioconjugation process, as has previously been shown for other protein carriers [45].

This first-in-human study paved the way for the bioconjugation technology to move forward with additional vaccine targets $[46,47]$, including a multivalent Shigella vaccine with $\mathrm{O}$ antigens from $S$. sonnei and from $S$. flexneri $2 \mathrm{a}, 6$ and $3 \mathrm{a}$, to provide broad coverage against the most prevalent Shigella O-antigen serotypes [2].

\subsection{Shigella Flexneri Bioconjugate Vaccine}

In the process of developing a multivalent Shigella vaccine, and to further demonstrate the robustness of the bioconjugation platform, another Shigella bioconjugate vaccine was generated and clinically evaluated. The $\mathrm{O}$ antigen from $S$. flexneri 2 a was chosen based on its high prevalence in endemic shigellosis. It also offered the possibility to use an existing human challenge model for preliminary evaluation of vaccine efficacy, thus advancing the 
development of a Shigella bioconjugate. The same protein carrier previously used for the O1 bioconjugate, EPA, was selected.

The initial phase I study [16] was conducted in a single centre at the NMRC (Naval Medical Research Center) to evaluate the safety and immunogenicity of the vaccine. Thirty healthy adult volunteers were enrolled in the study and received two injections one month apart of $10 \mu \mathrm{g}$ polysaccharide of the $S$. flexneri 2a bioconjugate (called Flexyn2a), alone or in combination with an aluminium adjuvant.

Safety and immunogenicity of this second prototype bioconjugate vaccine were confirmed, and similar to the observations in the study with the dysenteriae vaccine, immunization with Flexyn2a elicited a significant increase in IgG and IgA titres against S. flexneri 2a LPS (see Table 1). Both vaccine groups, with or without adjuvant, showed a $\geq 16$-fold increase in S. flexneri 2a-specific IgG and IgA GMT after the first dose, and overall, $\geq 92 \%$ of the participants seroconverted ( $\geq 4$-fold increase from baseline). Analysis between groups did not show significant differences between the adjuvanted and nonadjuvanted groups or between first or second injection, although the study was not powered to identify differences. Despite the small sample size analysed, the lack of difference observed could indicate that a single injection without adjuvant is sufficient to generate an immune response in the adult population. Functionality of the vaccine-induced antibody responses was confirmed by serum bactericidal assay (SBA). In addition, $S$. flexneri 2 a-specific antibody-secreting plasma cells (IgA and IgG) could be identified following vaccination.

The positive results obtained in this phase 1 trial warranted the further evaluation of the prototype monovalent vaccine Flexyn 2a in the controlled human infection model (CHIM study) to provide a preliminary basis to evaluate vaccine efficacy.

The randomized, double-blinded and placebo-controlled phase $2 \mathrm{~b}$ trial [19] was conducted at the Johns Hopkins Bloomberg School of Public Health. Sixty-seven participants received two injections of $10 \mu \mathrm{g}$ of Flexyn2a vaccine or placebo, one month apart. One month after the second dose, 59 participants received a target oral challenge of 1500 CFU (colony-forming units) of S. flexneri 2a strain 2457T (see Table 1).

The vaccine showed a good safety profile, similar to what was observed in the phase I study. In terms of immunogenicity, after the first dose the IgG responses already increased around 10-fold compared to baseline. The second vaccination or the subsequent challenge did not further increase the antibody titers of vaccinees, which stayed significantly higher when compared to the level reached in placebo recipients following challenge (2.5-fold increase in IgG titers in placebo recipients). In terms of responders (recipients who had at least a 4-fold increase in IgG), four weeks after the first dose the responder rate was $76.5 \%$, and four weeks after the second dose the rate was $81.8 \%$. As described in more detail in Clarkson et al. [25], several other parameters were investigated in this study, including memory B-cell responses, bactericidal assays and gut-homing LPS-specific antibody responses. All confirmed that the vaccine induced a robust and functional systemic immune response and supported activation of a vaccine-specific response at the mucosal level as well.

To determine the efficacy of the vaccine, the primary definition of established shigellosis included "severe diarrhea" (six or $>800 \mathrm{~g}$ loose stools within $24 \mathrm{~h}$ ) or "moderate diarrhea (four to five or 401-800 g loose stools within $24 \mathrm{~h}$ ) with fever or with one or more moderate constitutional or enteric symptom" or "dysentery" (which included at least two loose stools with gross blood within $24 \mathrm{~h}$ and any reportable constitutional symptom). Based on this definition, vaccine efficacy (VE) was 30\% (13/30 vs. 18/29; $p=0.11 ; 95 \%$ CI: -15 to 62.6$)$. However, vaccination with the bioconjugate was observed to have conferred significant protection against more severe diarrhea $(\geq 10$ or $\geq 1000 \mathrm{~g}$ loose stools within $24 \mathrm{~h}$ ) with a $72 \%$ efficacy ( $2 / 30$ vs. $7 / 29 ; p=0.07 ; 95 \% \mathrm{CI}$ : -9.5 to 64.3$)$, reduced severity of symptoms and was efficacious toward additional clinical endpoints including antibiotic administration and need for oral rehydration. The efficacy of the bioconjugate against more severe clinical outcomes of shigellosis was then confirmed with a post hoc analysis, whereby more severe shigellosis criteria were considered, such as fever or severe 
symptoms (rather than moderate or mild symptoms as in the per-protocol primary endpoint) along with diarrhea (at least moderate). The remarkably higher VE, namely $51.7 \%$ $(8 / 30$ vs. $16 / 29 ; p=0.02 ; 95 \%$ CI: 5.3 to 77.9$)$, obtained with the more severe shigellosis definition indicated that the vaccine was indeed efficacious. A shigellosis definition based on more severe outcomes was more appropriate for demonstrating vaccine efficacy in the context of the CHIM, as well as better reflecting the most disabling symptoms for subjects with shigellosis.

As described in Talaat et al., efficacy of the bioconjugate was additionally confirmed by different analyses, including a shigellosis disease score. This was shown to be lower in vaccinees, even those who developed shigellosis, than in placebo recipients, further demonstrating that even if disease was not totally prevented by vaccination, the severity was decreased.

In general, the study showed a clear association between immune responses elicited by vaccination, and protection against shigellosis after oral challenge, with 2a-LPS specific serum IgG responses being the parameter best associated with protection. Lower shedding was also reported for those vaccinees with the highest level of anti Sf2a-LPS IgG and vice versa for vaccinees with a weaker IgG response, suggesting a role for anti-Sf2a LPS serum IgG in limiting bacterial replication in the gut. In terms of duration of response, approximately one-year post-vaccination, the level of anti SF2a LPS-serum IgG in the vaccinated group was still significantly higher than at baseline, and significantly higher compared to challenged placebo recipients. Exploratory analyses performed as part of this study also showed activation of mucosal immunity following parenteral immunization and association between such mucosal responses and protection against disease [48].

\subsection{Quadrivalent Shigella Bioconjugate Vaccine}

The promising results obtained with the Flexyn2a prototype further supported the development of a multivalent bioconjugate vaccine, aiming to provide broad protection against the most prevalent serotypes of Shigella. The S4V is a quadrivalent bioconjugate vaccine which carries O-antigens of Shigella flexneri serotypes 2a, 3a, 6 and Shigella sonnei bioconjugated to the EPA carrier protein. These $\mathrm{O}$ antigens were chosen as they are from the most prevalent strains and will enable coverage to reach around $85 \%$ [49]. Based on Shigella incidence data from the GEMS study [50], such a vaccine may result in a direct coverage of $64 \%$. Additional coverage of approximately $20 \%$ toward Shigella serotypes not included in the vaccine could be reached because of cross reactivity, as previously shown preclinically with immune sera against 2a and 3a Shigella serotypes [2].

A phase $1 / 2$ dose-finding and age-descending (adults-children-infants) double-blind study is currently ongoing in Kenya with $\mathrm{S} 4 \mathrm{~V}$ to evaluate vaccine safety and immunogenicity in the target population of 9-month-old infants (NCT04056117). The trial has enrolled about 600 participants at two Kenya Medical Research Institute (KEMRI) sites in Kilifi and Kericho. Four different doses with or without aluminum adjuvant are being evaluated with a two-dose vaccination schedule at 9 and 12 months followed by a booster 6 months later. The data collected in this study will be an important step in the development of a Shigella vaccine to help protect the most vulnerable populations in low-income countries and will also contribute to the scientific knowledge around immune responses against Shigella $\mathrm{O}$ antigens in the pediatric population. The study completion is planned for the beginning of 2023 , with results expected to be available during 2023 . A positive outcome for safety and immunogenicity from this trial will significantly support pivotal efficacy trials with the Shigella bioconjugate in the target pediatric population, as well as in travelers and military personnel going to Shigella endemic regions.

\section{Outlook and Conclusions}

Although there have been many years of effort, a safe and efficacious vaccine against Shigella is not yet available. With the incorporation of molecular diagnostics, the burden of Shigella disease is now clearer than ever and a Shigella vaccine will have a significant 
impact in reducing morbidity, mortality and antimicrobial resistance. Although efforts to improve hygiene and appropriate sanitation may help to reduce the incidence of shigellosis, an effective vaccine remains a priority. According to the 2018 Wellcome Trust report "Vaccines to Tackle Drug Resistant Infections", enteric diseases have a massive impact on the development of antimicrobial resistance due to the quantity of antibiotics used to treat these infections. As reported, experts believe that a vaccine which helps to reduce disease severity, even if it does not prevent disease completely, will be valuable in decreasing the use of antibiotics.

An ideal Shigella vaccine needs to be safe and effective in infants, children, and adults, and simple and affordable to manufacture. The bioconjugate Shigella vaccine could fulfil all these characteristics. From the mechanisms of action, bioconjugate vaccines are expected to perform the same as other conjugate vaccines. Conjugate vaccines have been demonstrated to be well-tolerated and are routinely used to protect against several childhood diseases. There are several examples of successful conjugates vaccines on the market which generate immunity and long-lasting protection. Therefore, the expectations are that the bioconjugate Shigella vaccine will generate an adequate immune response in infants and children. The safety, immunogenicity and efficacy data collected during phase I and 2b (CHIM) studies with Flexyn2a in adults confirmed that the technology is appropriate for the generation of an effective Shigella vaccine.

From the manufacturing perspective, bioconjugation technology is very promising and can produce a low-cost vaccine due to the simplicity of the technology and reduced manufacturing steps. By producing the vaccines in a well-established biological system and avoiding chemical steps, bioconjugation technology generates a homogeneous product with low batch variability and few analytical requirements.

In this review, we summarize the development of the bioconjugate Shigella vaccine. This is, to our knowledge, the most advanced active program in the Shigella field. With the observed efficacy against severe shigellosis outcomes, the phase $2 b$ challenge trial provided clinical proof of concept of efficacy with the monovalent bioconjugate. In addition, it derisked and streamlined the development of $S 4 \mathrm{~V}$, the final multivalent product. In the ongoing clinical trial, it remains to be seen if the quadrivalent bioconjugate vaccine can generate significant immunogenicity above the level of preexisting antibodies in children and in immunologically naïve infants. This being the case, there is hope that this quadrivalent bioconjugate could be efficacious against disease.

Indeed, though results identifying a correlate of protection $(\mathrm{CoP})$ are still considered preliminary, the strong association with protection identified for serum IgG with the Flexyn2a bioconjugate is in line with previous reports on the relevance of serum $\operatorname{IgG}$ in protection against shigellosis. In particular, field studies in Israel with the chemical conjugate vaccine for $S$. sonnei, with a $70 \%$ efficacy against shigellosis in children $>3$ years old [22], highlighted the association between anti-LPS serum IgG and protection against shigellosis. Results of the CHIM study with Flexyn2a confirmed these previous findings and highlighted the importance of a strong serum antibody response against Shigella-LPS to achieve protection against disease. Although different immunization strategies (oral, parenteral, intranasal, etc.) may ultimately result in multiple CoP (mechanistic or not), at least for parenteral immunization, anti-LPS serum IgG titers are currently supported as a candidate for CoP.

It is important to note that the size of the inoculum administered in a CHIM (significantly higher than what is usually seen in nature) may set an artificially high bar for a vaccine candidate, potentially resulting in lower efficacy in this setting than would be observed for the same vaccine candidate in a field trial. However, human challenge trials generally represent a powerful tool to elucidate the pathogenesis of diseases, identify $\mathrm{CoP}$ and accelerate the development of vaccines, as shown for cholera or typhoid vaccines [51,52]. To accelerate the development of the bioconjugate vaccine, one strategy could be the demonstration of efficacy against Shigella sonnei and Flexneri 2a, the two serotypes for which a CHIM is established. The S4V quadrivalent vaccine could then 
be used, accompanied by collection of additional safety, immunogenicity and possibly preliminary field-efficacy data, in the target population of infants. Full confirmation of efficacy could follow in postlicensure phase IV studies [53]. Such a strategy could avoid long and costly phase 3 field studies and ensure earlier delivery of a vaccine highly needed in the pediatric population. At the same time, these results could support licensure of the Shigella vaccine for travelers or military. It will be important to work with regulatory agencies to identify any possible nontraditional paths to licensure in order to bring a safe and efficacious vaccine to populations who need it in the shortest time possible.

Author Contributions: P.M. and C.A. conceptualized the manuscript and draft writing and finalization of the paper. All authors have read and agreed to the published version of the manuscript.

Funding: The vaccine work was supported by Wellcome Trust (211475/Z/18/Z) and GSK. The manuscript was supported by Bill and Melinda Gates foundation.

Institutional Review Board Statement: All studies described with Shigella bioconjugates were conducted in accordance with the Declaration of Helsinki, and approved by the competent Institutional Review Boards (or Ethics Committee). The ongoing study with S4V bioconjugate is conducted in accordance with the Declaration of Helsinki, and approved by the Institutional Review Board of KEMRI-CGMR-Cost and KEMRI MRD-K, Kericho (protocol code S4V01 and date of approval 10 July 2019).

Informed Consent Statement: Informed consent was obtained from all subjects involved in the study.

Data Availability Statement: Not applicable.

Acknowledgments: We thank Laura Yates and Paul Wolfrom for their review of the manuscript and Michael Kowarik for his support in preparation of Figure 1.

Conflicts of Interest: The authors of this review are employees of LimmaTech Biologics. The funders had no role in the design of the study; in the collection, analyses, or interpretation of data; in the writing of the manuscript, or in the decision to publish the results.

\section{References}

1. Kotloff, K.L.; Platts-Mills, J.A.; Nasrin, D.; Roose, A.; Blackwelder, W.C.; Levine, M.M. Global burden of diarrheal diseases among children in developing countries: Incidence, etiology, and insights from new molecular diagnostic techniques. Vaccine 2017, 35, 6783-6789. [CrossRef] [PubMed]

2. Livio, S.; Strockbine, N.A.; Panchalingam, S.; Tennant, S.M.; Barry, E.M.; Marohn, M.E.; Antonio, M.; Hossain, A.; Mandomando, I.; Ochieng, J.B.; et al. Shigella isolates from the global enteric multicenter study inform vaccine development. Clin. Infect. Dis. 2014, 59, 933-941. [CrossRef] [PubMed]

3. Giersing, B.; Khalil, I. DRAFT WHO Preferred Product Characteristics for Vaccines against Shigella. Available online: https:/ / www.who.int/immunization/research/ppc-tpp/PPC_Shigella_draft_for_review_april2020.pdf (accessed on 16 December 2021).

4. Baker, S.; The, H.C. Recent insights into Shigella. Curr. Opin. Infect. Dis. 2018, 31, 449-454. [CrossRef] [PubMed]

5. Kotloff, K.L.; Riddle, M.S.; Platts-Mills, J.A.; Pavlinac, P.; Zaidi, A.K.M. Shigellosis. Lancet 2018, 391, 801-812. [CrossRef]

6. Chompook, P. Shigellosis. Encycl. Environ. Health 2019, 626-632. [CrossRef]

7. Worley, J.N.; Javkar, K.; Hoffmann, M.; Hysell, K.; Garcia-Williams, A.; Tagg, K.; Kanjilal, S.; Strain, E.; Pop, M.; Allard, M.; et al Genomic Drivers of Multidrug-Resistant Shigella Affecting Vulnerable Patient Populations in the United States and Abroad. Mbio 2021, 12, e03188-20. [CrossRef] [PubMed]

8. U.S. Centers for Disease Control and Prevention. Antibiotic resistance threats in the United States-2019. 2019. Available online: https:/ / www.cdc.gov/drugresistance/pdf/threats-report/2019-ar-threats-report-508.pdf (accessed on 21 October 2021).

9. Kahsay, A.G.; Muthupandian, S. A review on Sero diversity and antimicrobial resistance patterns of Shigella species in Africa, Asia and South America, 2001-2014. BMC Res. Notes 2016, 9, 422. [CrossRef]

10. Ashkenazi, S.; Cohen, D. An update on vaccines against Shigella. Ther. Adv. Vaccines 2013, 1, 113-123. [CrossRef] [PubMed]

11. Shimanovich, A.A.; Buskirk, A.D.; Heine, S.J.; Blackwelder, W.C.; Wahid, R.; Kotloff, K.L.; Pasetti, M.F. Functional and AntigenSpecific Serum Antibody Levels as Correlates of Protection Against Shigellosis in a Controlled Human Challenge Study. Clin. Vaccine Immunol. 2016, 24, e00412-16. [CrossRef]

12. Raqib, R.; Sarker, P.; Zaman, K.; Alam, N.H.; Wierzba, T.F.; Maier, N.; Talukder, K.; Baqui, A.H.; Suvarnapunya, A.E.; Qadri, F.; et al. A phase I trial of WRSS1, a Shigella sonnei live oral vaccine in Bangladeshi adults and children. Hum. Vaccin Immunother. 2019, 15, 1326-1337. [CrossRef] 
13. Frenck, R.W.; Baqar, S.; Alexander, W.; Dickey, M.; McNeal, M.; El-Khorazaty, J.; Baughman, H.; Hoeper, A.; Barnoy, S.; Suvarnapunya, A.E.; et al. A Phase I trial to evaluate the safety and immunogenicity of WRSs2 and WRSs3; two live oral candidate vaccines against Shigella sonnei. Vaccine 2018, 36, 4880-4889. [CrossRef] [PubMed]

14. Chakraborty, S.; Harro, C.; DeNearing, B.; Bream, J.; Bauers, N.; Dally, L.; Flores, J.; Van de Verg, L.; Sack, D.A.; Walker, R. Evaluation of the Safety, Tolerability, and Immunogenicity of an Oral, Inactivated Whole-Cell Shigella flexneri 2a Vaccine in Healthy Adult Subjects. Clin. Vaccine Immunol. 2016, 23, 315-325. [CrossRef] [PubMed]

15. Cohen, D.; Atsmon, J.; Artaud, C.; Meron-Sudai, S.; Gougeon, M.-L.; Bialik, A.; Goren, S.; Asato, V.; Ariel-Cohen, O.; Reizis, A.; et al. Safety and immunogenicity of a synthetic carbohydrate conjugate vaccine against Shigella flexneri 2 a in healthy adult volunteers: A phase 1, dose-escalating, single-blind, randomised, placebo-controlled study. Lancet Infect. Dis. 2021, 21, 546-558. [CrossRef]

16. Riddle, M.S.; Kaminski, R.W.; Di Paolo, C.; Porter, C.K.; Gutierrez, R.L.; Clarkson, K.A.; Weerts, H.E.; Duplessis, C.; Castellano, A.; Alaimo, C.; et al. Safety and Immunogenicity of a Candidate Bioconjugate Vaccine against Shigella flexneri 2a Administered to Healthy Adults: A Single-Blind, Randomized Phase I Study. Clin. Vaccine Immunol. 2016, 23, 908-917. [CrossRef] [PubMed]

17. Launay, O.; Ndiaye, A.G.W.; Conti, V.; Loulergue, P.; Sciré, A.S.; Landre, A.M.; Ferruzzi, P.; Nedjaai, N.; Schütte, L.D.; Auerbach, J.; et al. Booster Vaccination With GVGH Shigella sonnei 1790GAHB GMMA Vaccine Compared to Single Vaccination in Unvaccinated Healthy European Adults: Results From a Phase 1 Clinical Trial. Front. Immunol. 2019, 10, 335. [CrossRef]

18. Mo, Y.; Fang, W.; Li, H.; Chen, J.; Hu, X.; Wang, B.; Feng, Z.; Shi, H.; He, Y.; Huang, D.; et al. Safety and Immunogenicity of a Shigella Bivalent Conjugate Vaccine (ZF0901) in 3-Month- to 5-Year-Old Children in China. Vaccines 2022, 10, 33. [CrossRef]

19. Talaat, K.R.; Alaimo, C.; Martin, P.; Bourgeois, A.L.; Dreyer, A.M.; Kaminski, R.W.; Porter, C.K.; Chakraborty, S.; Clarkson, K.A.; Brubaker, J.; et al. Human challenge study with a Shigella bioconjugate vaccine: Analyses of clinical efficacy and correlate of protection. EBioMedicine 2021, 66, 103310. [CrossRef]

20. Frenck, R.W.; Conti, V.; Ferruzzi, P.; Ndiaye, A.G.W.; Parker, S.; McNeal, M.M.; Dickey, M.; Granada, J.P.; Cilio, G.L.; de Ryck, I.; et al. Efficacy, safety, and immunogenicity of the Shigella sonnei 1790GAHB GMMA candidate vaccine: Results from a phase $2 b$ randomized, placebo-controlled challenge study in adults. EClinicalMedicine 2021, 39, 101076. [CrossRef]

21. Kotloff, K.L.; Losonsky, G.A.; Nataro, J.P.; Wasserman, S.S.; Hale, T.L.; Taylor, D.N.; Newland, J.W.; Sadoff, J.C.; Formal, S.B.; Levine, M.M. Evaluation of the safety, immunogenicity, and efficacy in healthy adults of four doses of live oral hybrid Escherichia coli-Shigella flexneri 2a vaccine strain EcSf2a-2. Vaccine 1995, 13, 495-502. [CrossRef]

22. Passwell, J.H.; Ashkenzi, S.; Banet-Levi, Y.; Ramon-Saraf, R.; Farzam, N.; Lerner-Geva, L.; Even-Nir, H.; Yerushalmi, B.; Chu, C.; Shiloach, J.; et al. Age-related efficacy of Shigella O-specific polysaccharide conjugates in 1-4-year-old Israeli children. Vaccine 2009, 28, 2231-2235. [CrossRef]

23. Cohen, D.; Ashkenazi, S.; Green, M.S.; Gdalevich, M.; Robin, G.; Slepon, R.; Yavzori, M.; Orr, N.; Block, C.; Ashkenazi, I.; et al. Double-blind vaccine-controlled randomised efficacy trial of an investigational Shigella sonnei conjugate vaccine in young adults. Lancet 1997, 349, 155-159. [CrossRef]

24. Obiero, C.W.; Ndiaye, A.G.W.; Sciré, A.S.; Kaunyangi, B.M.; Marchetti, E.; Gone, A.M.; Schütte, L.D.; Riccucci, D.; Auerbach, J.; Saul, A.; et al. A Phase 2a Randomized Study to Evaluate the Safety and Immunogenicity of the 1790GAHB Generalized Modules for Membrane Antigen Vaccine against Shigella sonnei Administered Intramuscularly to Adults from a Shigellosis-Endemic Country. Front. Immunol. 2017, 8, 909. [CrossRef] [PubMed]

25. Clarkson, K.A.; Talaat, K.R.; Alaimo, C.; Martin, P.; Bourgeois, A.L.; Dreyer, A.; Porter, C.K.; Chakraborty, S.; Brubaker, J.; Elwood, D.; et al. Immune response characterization in a human challenge study with a Shigella flexneri 2a bioconjugate vaccine. EBioMedicine 2021, 66, 103308. [CrossRef] [PubMed]

26. Goldblatt, D. Conjugate vaccines. Clin. Exp. Immunol. 2000, 119, 1-3. [CrossRef] [PubMed]

27. Pichichero, M.; Casey, J.; Blatter, M.; Rothstein, E.; Ryall, R.; Bybel, M.; Gilmet, G.; Papa, T. Comparative trial of the safety and immunogenicity of quadrivalent (A, C, Y, W-135) meningococcal polysaccharide-diphtheria conjugate vaccine versus quadrivalent polysaccharide vaccine in two- to ten-year-old children. Pediatric Infect. Dis. J. 2005, 24, 57-62. [CrossRef]

28. MacDonald, N.E.; Halperin, S.A.; Law, B.J.; Forrest, B.; Danzig, L.E.; Granoff, D.M. Induction of immunologic memory by conjugated vs plain meningococcal C polysaccharide vaccine in toddlers: A randomized controlled trial. JAMA 1998, 280, 1685-1689. [CrossRef]

29. Englund, J.A.; Glezen, W.P.; Turner, C.; Harvey, J.; Thompson, C.; Siber, G.R. Transplacental antibody transfer following maternal immunization with polysaccharide and conjugate Haemophilus influenzae type b vaccines. J. Infect. Dis. 1995, 171, 99-105. [CrossRef] [PubMed]

30. Lu, C.-L.; Chang, S.-Y.; Chuang, Y.-C.; Liu, W.-C.; Su, C.-T.; Su, Y.-C.; Chang, S.-F.; Hung, C.-C. Revaccination with 7-valent pneumococcal conjugate vaccine elicits better serologic response than 23-valent pneumococcal polysaccharide vaccine in HIVinfected adult patients who have undergone primary vaccination with 23-valent pneumococcal polysaccharide vaccine in the era of combination antiretroviral therapy. Vaccine 2014, 32, 1031-1035. [CrossRef]

31. Sorensen, R.U.; Leiva, L.E.; Giangrosso, P.A.; Butler, B.; Javier, F.C.; Sacerdote, D.M.; Bradford, N.; Moore, C. Response to a heptavalent conjugate Streptococcus pneumoniae vaccine in children with recurrent infections who are unresponsive to the polysaccharide vaccine. Pediatric Infect. Dis. J. 1998, 17, 685-691. [CrossRef]

32. Pichichero, M.E. Meningococcal conjugate vaccine in adolescents and children. Clin. Pediatr. 2005, 44, 479-489. [CrossRef]

33. Watson, W. Pneumococcal conjugate vaccines. Pediatric Infect. Dis. J. 2000, 19, 331-332. [CrossRef] [PubMed] 
34. Slack, M.; Esposito, S.; Haas, H.; Mihalyi, A.; Nissen, M.; Mukherjee, P.; Harrington, L. Haemophilus influenzae type b disease in the era of conjugate vaccines: Critical factors for successful eradication. Expert Rev. Vaccines 2020, 19, 903-917. [CrossRef] [PubMed]

35. Feldman, M.F.; Wacker, M.; Hernandez, M.; Hitchen, P.G.; Marolda, C.L.; Kowarik, M.; Morris, H.R.; Dell, A.; Valvano, M.A.; Aebi, M. Engineering N-linked protein glycosylation with diverse $\mathrm{O}$ antigen lipopolysaccharide structures in Escherichia coli. Proc. Natl. Acad. Sci. USA 2005, 102, 3016-3021. [CrossRef] [PubMed]

36. Wacker, M.; Linton, D.; Hitchen, P.G.; Nita-Lazar, M.; Haslam, S.M.; North, S.J.; Panico, M.; Morris, H.R.; Dell, A.; Wren, B.W.; et al N-linked glycosylation in Campylobacter jejuni and its functional transfer into E. coli. Science 2002, 298, 1790-1793. [CrossRef] [PubMed]

37. Ahmed, A.; Li, J.; Shiloach, Y.; Robbins, J.B.; Szu, S.C. Safety and immunogenicity of Escherichia coli O157 O-specific polysaccharide conjugate vaccine in 2-5-year-old children. J. Infect. Dis. 2006, 193, 515-521. [CrossRef] [PubMed]

38. Ashkenazi, A.; Pai, R.C.; Fong, S.; Leung, S.; Lawrence, D.A.; Marsters, S.A.; Blackie, C.; Chang, L.; McMurtrey, A.E.; Hebert, A.; et al. Safety and antitumor activity of recombinant soluble Apo2 ligand. J. Clin. Investig. 1999, 104, 155-162. [CrossRef] [PubMed]

39. Taylor, D.N.; Trofa, A.C.; Sadoff, J.; Chu, C.; Bryla, D.; Shiloach, J.; Cohen, D.; Ashkenazi, S.; Lerman, Y.; Egan, W.; et al. Synthesis, characterization, and clinical evaluation of conjugate vaccines composed of the O-specific polysaccharides of Shigella dysenteriae type 1, Shigella flexneri type 2a, and Shigella sonnei (Plesiomonas shigelloides) bound to bacterial toxoids. Infect. Immun. 1993, 61, 3678-3687. [CrossRef] [PubMed]

40. Passwell, J.H.; Harlev, E.; Ashkenazi, S.; Chu, C.; Miron, D.; Ramon, R.; Farzan, N.; Shiloach, J.; Bryla, D.A.; Majadly, F.; et al. Safety and immunogenicity of improved Shigella O-specific polysaccharide-protein conjugate vaccines in adults in Israel. Infect. Immun. 2001, 69, 1351-1357. [CrossRef] [PubMed]

41. Passwell, J.H.; Ashkenazi, S.; Harlev, E.; Miron, D.; Ramon, R.; Farzam, N.; Lerner-Geva, L.; Levi, Y.; Chu, C.; Shiloach, J.; et al. Safety and immunogenicity of Shigella sonnei-CRM9 and Shigella flexneri type 2a-rEPAsucc conjugate vaccines in one- to four-yearold children. Pediatric Infect. Dis. J. 2003, 22, 701-706. [CrossRef]

42. Robbins, J.B.; Kubler-Kielb, J.; Vinogradov, E.; Mocca, C.; Pozsgay, V.; Shiloach, J.; Schneerson, R. Synthesis, characterization, and immunogenicity in mice of Shigella sonnei O-specific oligosaccharide-core-protein conjugates. Proc. Natl. Acad. Sci. USA 2009, 106, 7974-7978. [CrossRef]

43. Ravenscroft, N.; Haeuptle, M.A.; Kowarik, M.; Fernandez, F.S.; Carranza, P.; Brunner, A.; Steffen, M.; Wetter, M.; Keller, S.; Ruch, C.; et al. Purification and characterization of a Shigella conjugate vaccine, produced by glycoengineering Escherichia coli. Glycobiology 2016, 26, 51-62. [CrossRef] [PubMed]

44. Hatz, C.; Bally, B.; Rohrer, S.; Steffen, R.; Kramme, S.; Siegrist, C.-A.; Wacker, M.; Alaimo, C.; Fonck, V.G. Safety and immunogenicity of a candidate bioconjugate vaccine against Shigella dysenteriae type 1 administered to healthy adults: A single blind, partially randomized Phase I study. Vaccine 2015, 33, 4594-4601. [CrossRef] [PubMed]

45. Wacker, M.; Wang, L.; Kowarik, M.; Dowd, M.; Lipowsky, G.; Faridmoayer, A.; Shields, K.; Park, S.; Alaimo, C.; Kelley, K.A.; et al. Prevention of Staphylococcus aureus Infections by Glycoprotein Vaccines Synthesized in Escherichia coli. J. Infect. Dis. 2014, 209, 1551-1561. [CrossRef] [PubMed]

46. Huttner, A.; Hatz, C.; van den Dobbelsteen, G.; Abbanat, D.; Hornacek, A.; Frölich, R.; Dreyer, A.M.; Martin, P.; Davies, T.; Fae, K.; et al. Safety, immunogenicity, and preliminary clinical efficacy of a vaccine against extraintestinal pathogenic Escherichia coli in women with a history of recurrent urinary tract infection: A randomised, single-blind, placebo-controlled phase $1 \mathrm{~b}$ trial. Lancet Infect. Dis. 2017, 17, 528-537. [CrossRef]

47. Frenck, R.W.; Ervin, J.; Chu, L.; Abbanat, D.; Spiessens, B.; Go, O.; Haazen, W.; van den Dobbelsteen, G.; Poolman, J.; Thoelen, S.; et al. Safety and immunogenicity of a vaccine for extra-intestinal pathogenic Escherichia coli (ESTELLA): A phase 2 randomised controlled trial. Lancet Infect. Dis. 2019, 19, 631-640. [CrossRef]

48. Clarkson, K.A.; Porter, C.K.; Talaat, K.R.; Frenck, R.W.; Alaimo, C.; Martin, P.; Bourgeois, A.L.; Kaminski, R.W. Shigella-Specific Immune Profiles Induced after Parenteral Immunization or Oral Challenge with Either Shigella flexneri 2a or Shigella sonnei. mSphere 2021, 6, e0012221. [CrossRef]

49. Noriega, F.R.; Liao, F.M.; Maneval, D.R.; Ren, S.; Formal, S.B.; Levine, M.M. Strategy for cross-protection among Shigella flexneri serotypes. Infect. Immun. 1999, 67, 782-788. [CrossRef]

50. Kotloff, K.L.; Nataro, J.P.; Blackwelder, W.C.; Nasrin, D.; Farag, T.H.; Panchalingam, S.; Wu, Y.; Sow, S.O.; Sur, D.; Breiman, R.F.; et al. Burden and aetiology of diarrhoeal disease in infants and young children in developing countries (the Global Enteric Multicenter Study, GEMS): A prospective, case-control study. Lancet 2013, 382, 209-222. [CrossRef]

51. Chen, W.H.; Cohen, M.B.; Kirkpatrick, B.D.; Brady, R.C.; Galloway, D.; Gurwith, M.; Hall, R.H.; Kessler, R.A.; Lock, M.; Haney, D.; et al. Single-dose Live Oral Cholera Vaccine CVD 103-HgR Protects Against Human Experimental Infection With Vibrio cholerae O1 El Tor. Clin. Infect. Dis. 2016, 62, 1329-1335. [CrossRef]

52. Jin, C.; Gibani, M.M.; Moore, M.; Juel, H.B.; Jones, E.; Meiring, J.; Harris, V.; Gardner, J.; Nebykova, A.; Kerridge, S.A.; et al. Efficacy and immunogenicity of a Vi-tetanus toxoid conjugate vaccine in the prevention of typhoid fever using a controlled human infection model of Salmonella Typhi: A randomised controlled, phase $2 \mathrm{~b}$ trial. Lancet 2017, 390, 2472-2480. [CrossRef]

53. Giersing, B.K.; Porter, C.K.; Kotloff, K.; Neels, P.; Cravioto, A.; MacLennan, C.A. How can controlled human infection models accelerate clinical development and policy pathways for vaccines against Shigella? Vaccine 2019, 37, 4778-4783. [CrossRef] [PubMed] 